\title{
TEM Analysis of Interfaces in Diffusion-Bonded Silicon Carbide Ceramics Joined Using Metallic Interlayers
}

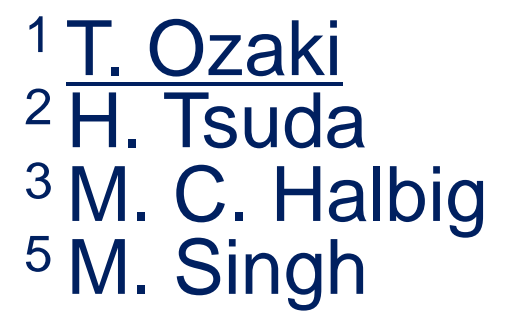

1 Y. Hasegawa

$2 \mathrm{~S}$. Mori

${ }^{4}$ R. Asthana

1Technology Research Institute of Osaka Prefecture, Osaka, Japan 2Osaka Prefecture University, Osaka, Japan 3NASA Glenn Research Center, Cleveland, Ohio, USA 4University of Wisconsin-Stout, Menomonie, WI, USA ${ }^{5}$ Ohio Aerospace Institute, Cleveland, Ohio, USA

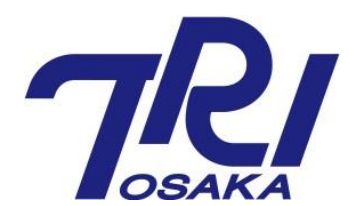

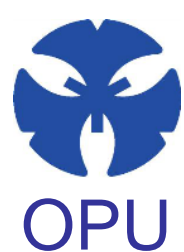

NASA

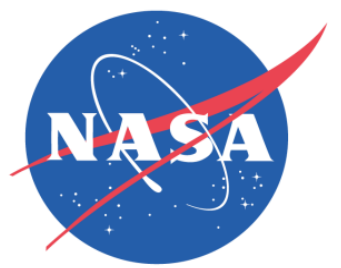

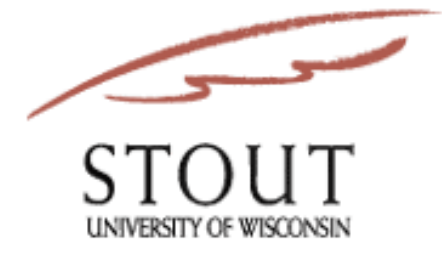




\section{outline}

1. Introduction

properties and applications of SiC

2. Sample preparations used for diffusion bonding

Substrates : SA-Tyrannohex ${ }^{\mathrm{TM}}$ (SA-THX)

Interlayers : Ti-Mo foil

3. Experimental results

TEM and STEM images of substrates (SA-THX)

TEM and STEM images of diffusion bonded samples

4. Discussion about the microstructure of the formed phases by diffusion bonding

the orientation relation between the precipitated $\mathrm{TiC}$ and Mo-Ti (SS)

5. Summary 


\section{Mismatch of elastic modulus (E) and coefficient of thermal expansion (CTE; $\alpha$ ) between substrate and interlayer}

We have to pay attention to mismatch of elastic modulus and CTE when we select interlayer material to join SiC.
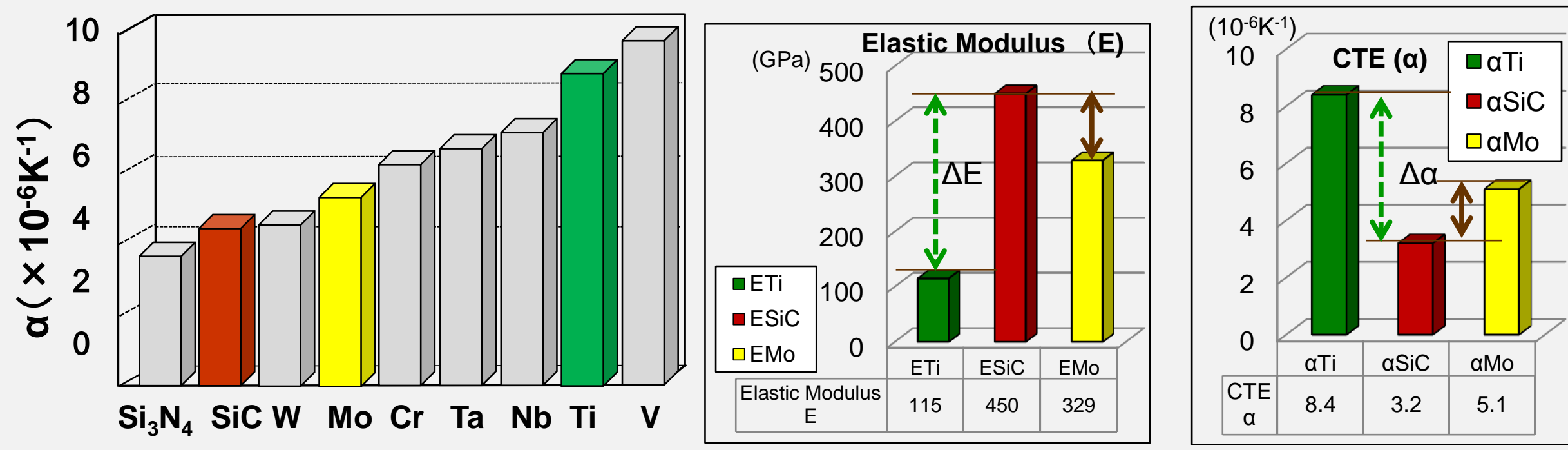

Both $E$ and CTE of Mo is closer to $\mathrm{SiC}$ than that of $\mathrm{Ti}$.

- Ti and Mo have been used to join $\alpha$ - SiC.

- Better quality bonds formed with Mo than with Ti. But,

- Ti can lower the diffusion bonding temperature.

Therefore, Ti-Mo bilayer that possesses both advances of $\mathrm{Ti}$ and Mo is also very attractive.

Therefore in this work, we utilize Ti-Mo as interlayers. 


\section{Diffusion Bonding of a SA-THX using Ti/Mo metallic Interlayers}

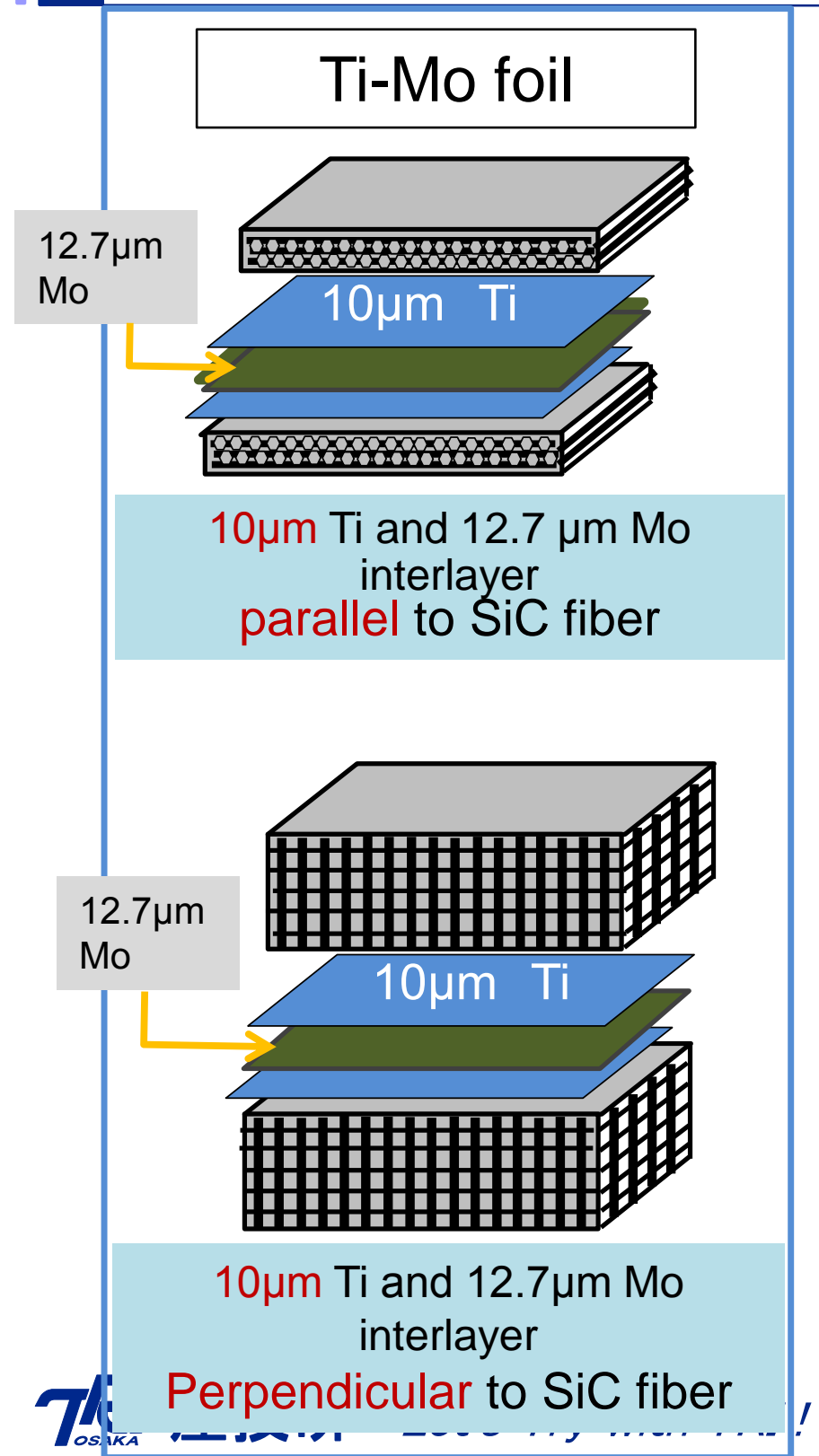

Used sample

@NASA

SA-THX ...SiC fiber-bonded ceramics, UBE Industries

Ti-foil Mo-foil

Bonding structure

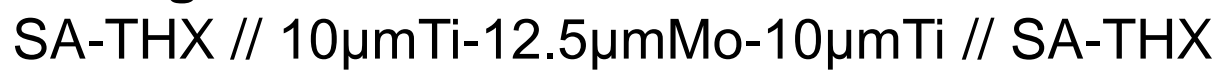
Bonding process

Hot-press in $1200^{\circ} \mathrm{C}$, 4hour, vacuum 30MPa

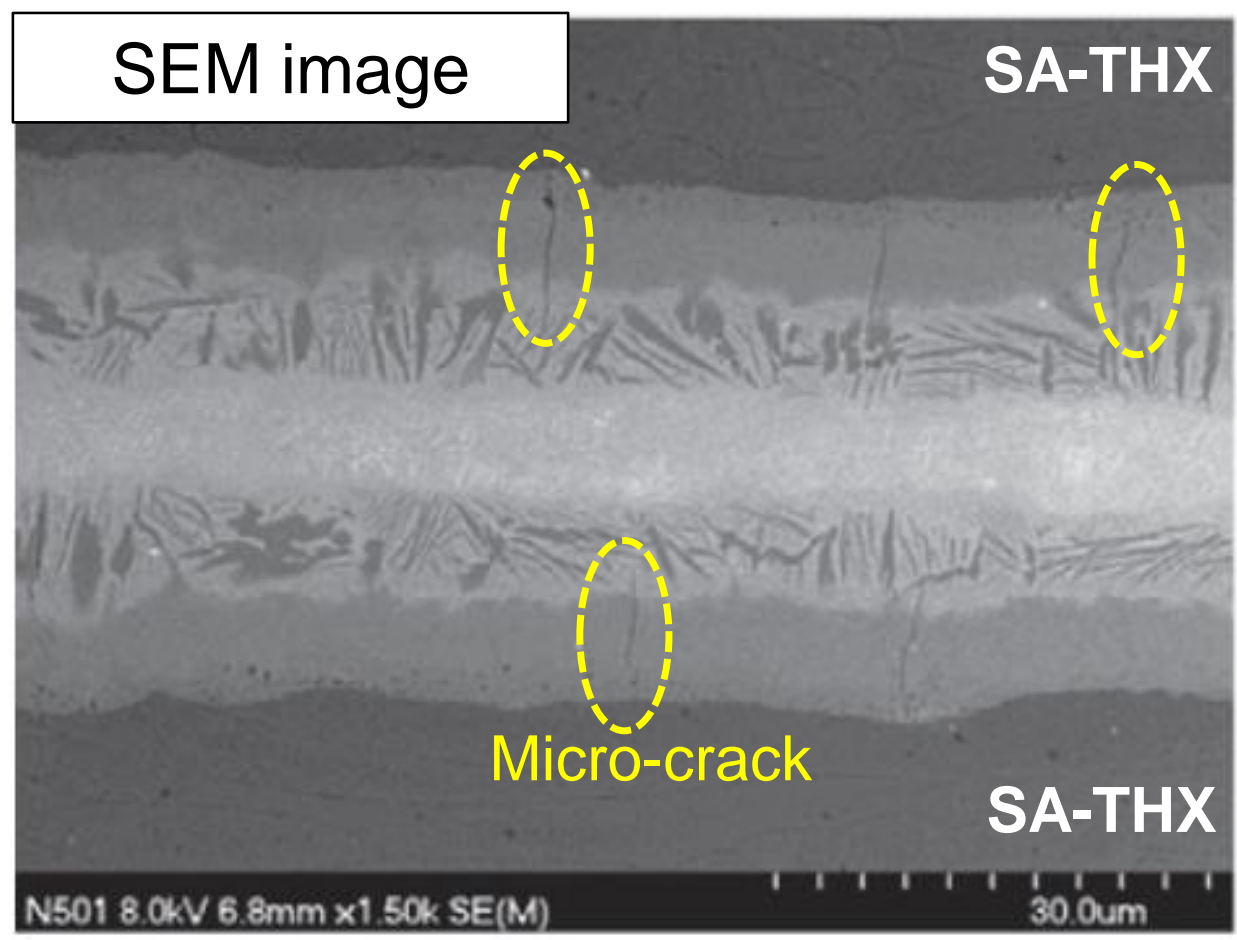

M.C. Halbig, et. al., Ceramics International41(2015)2140-2149 
Until now, the phases formed during diffusion bonding have been studied $\cdots \cdot$. (to join $\mathrm{SiC}-\mathrm{SiC}$ using Ti interlayer)

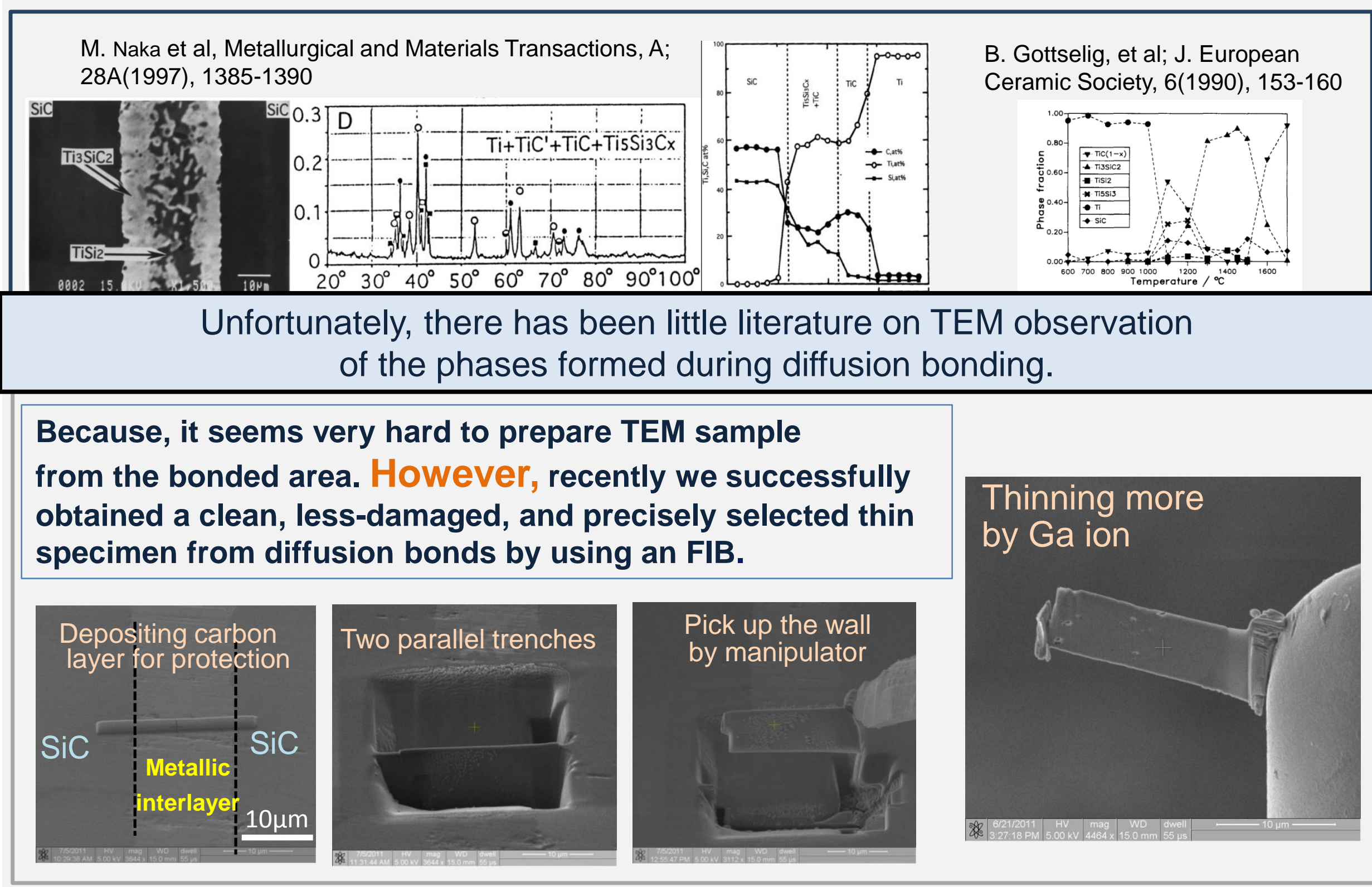




\section{Objectives}

We diffusion bonded $\mathrm{SiC}$ and $\mathrm{SiC}$ ( $\underline{\underline{\mathrm{SA}}-\mathrm{THX} \text { and SA-THX) }}$ using Ti-Mo foil metallic interlayer.

We carried out TEM and STEM observations with the diffusion bonded sample prepared by FIB technique.

1. Evaluate microstructures of the diffusion bonded SA-THX by TEM and STEM.

2. Characterize the complex microstructure in the diffusion bonded area by TEM observation and SAED analysis. 


\section{FIB and Cs-corrected STEM}

Focused Ion Beam, FIB (Hitachi FB-2200)

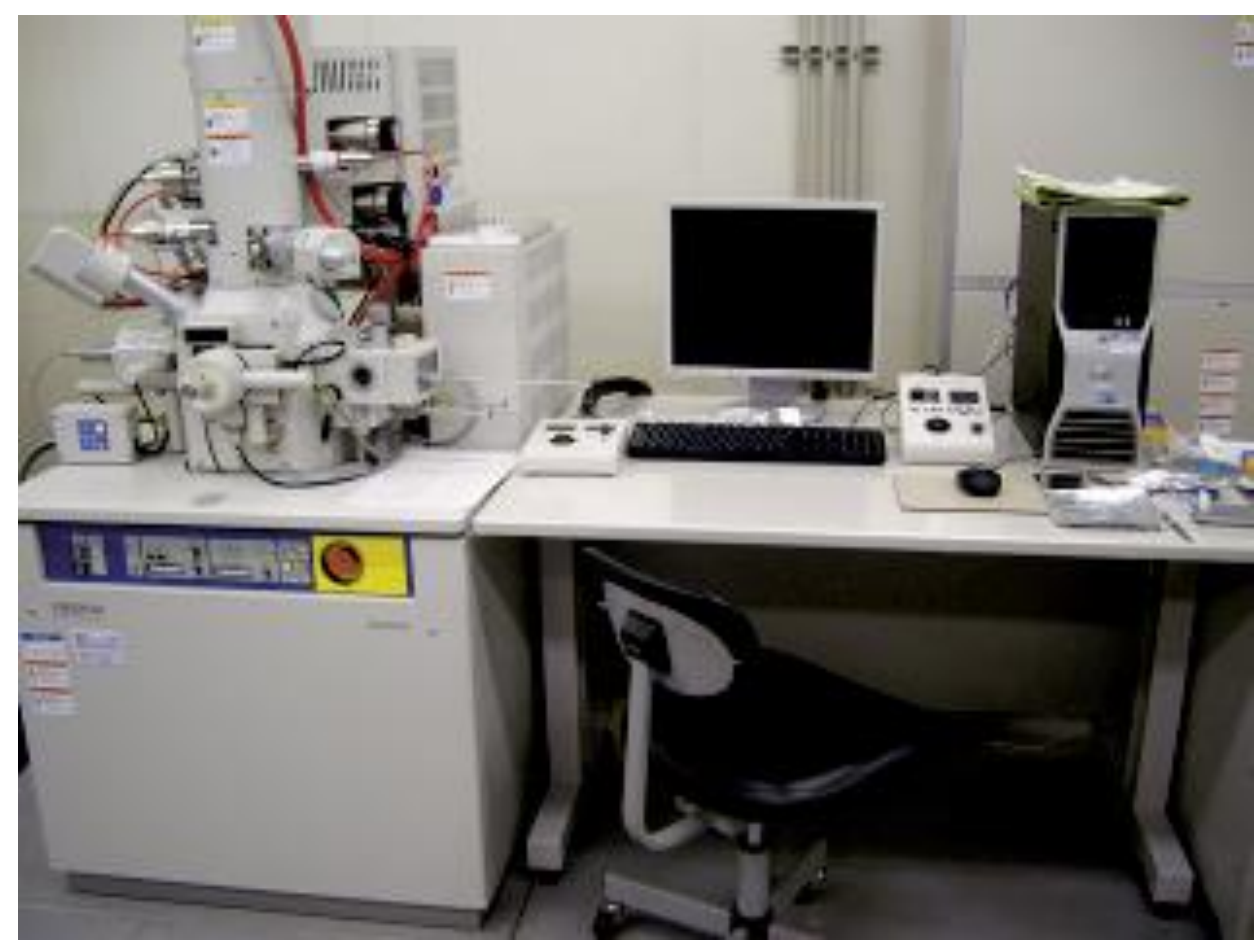

Prepared thin samples for TEM and STEM.

T Posaka 産技研 Let's Try with TRI!
Cs-corrected STEM

(Hitachi HD-2700)

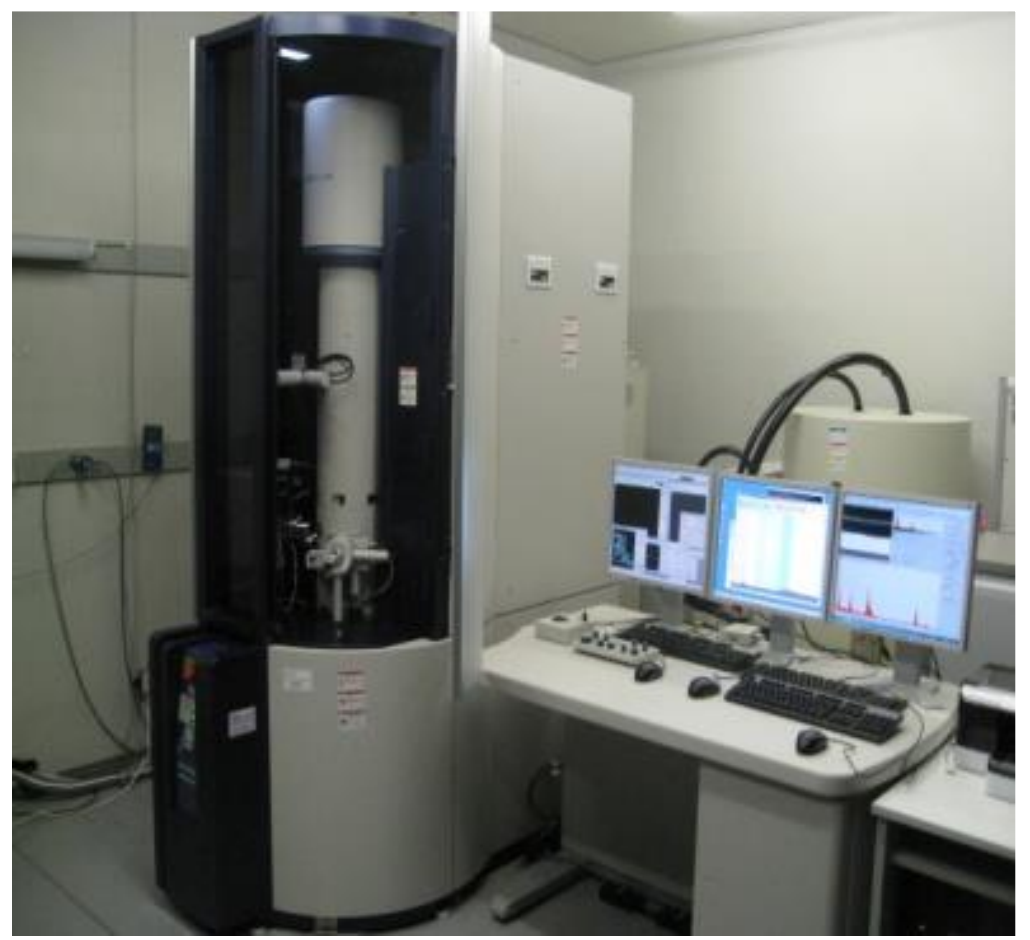

Checked the thin samples prepared by FIB.

Three-Observation mode:

SEM, BF-STEM and HAADF 
Fabricating procedure of the thin sample (SIM image obtained by FIE
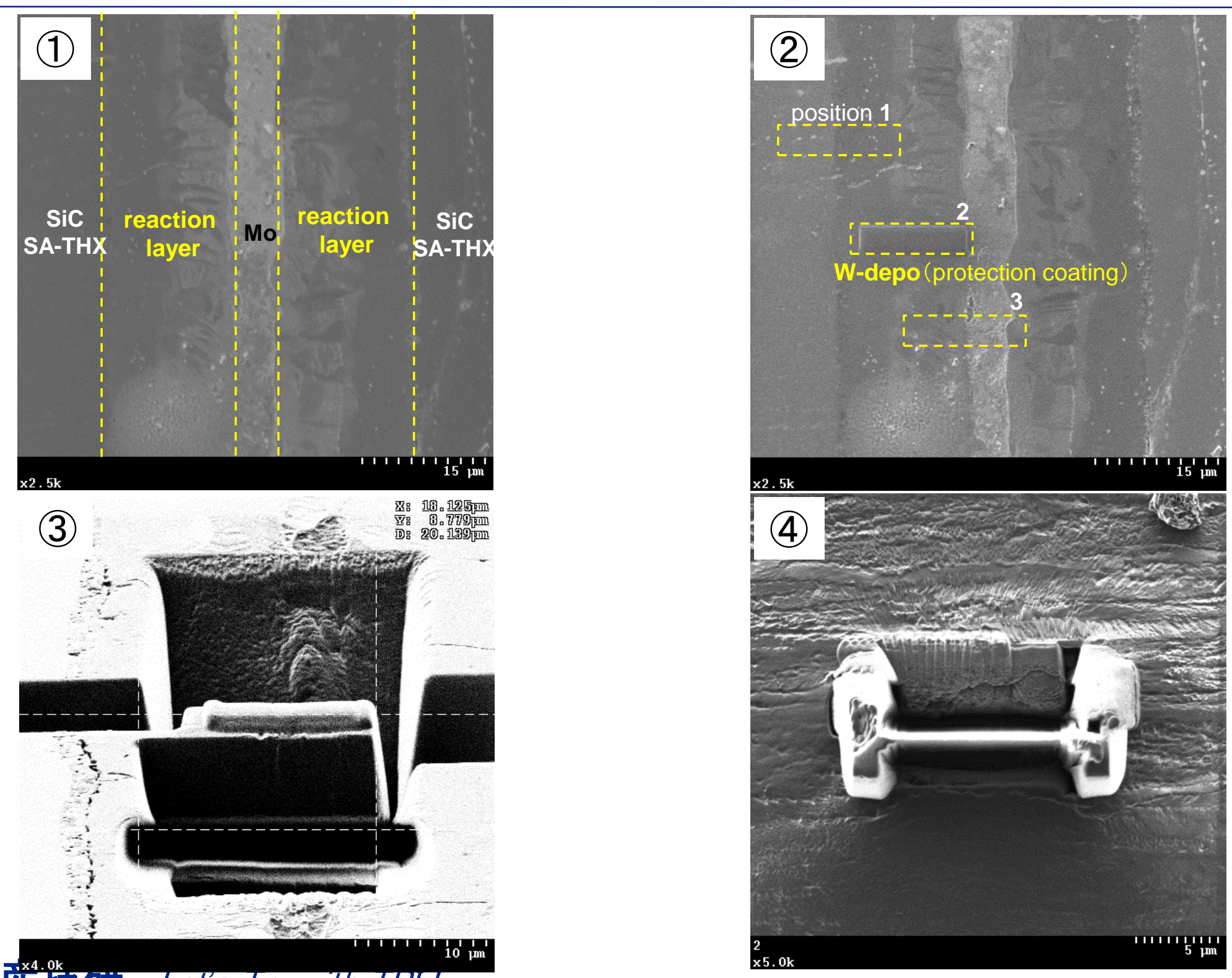

Tosaka 産技研 Let's Iry with IRI!

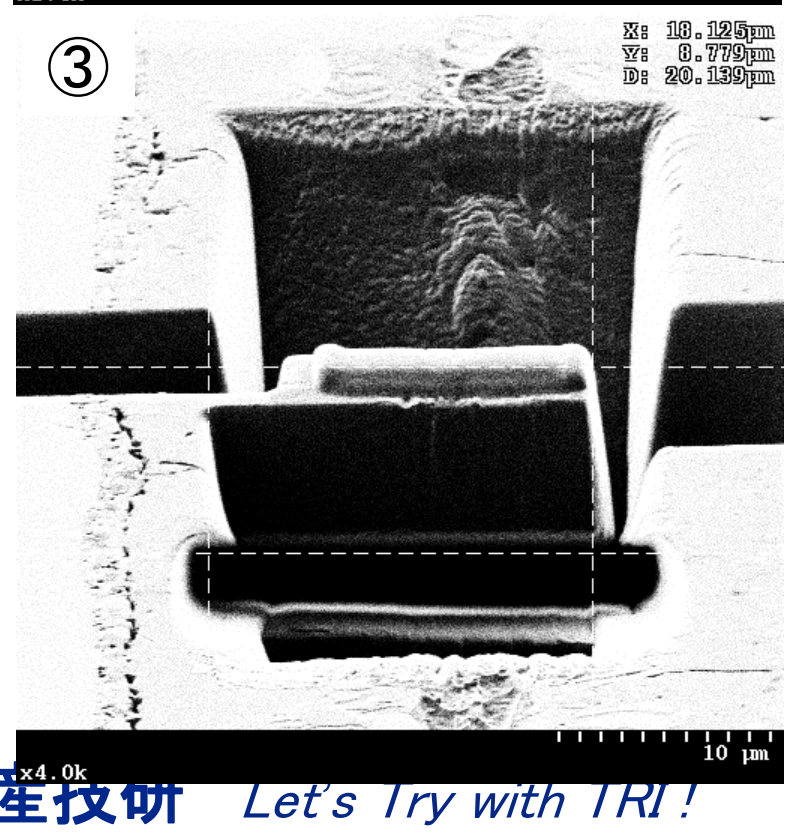




\section{STEM observation of the FIB sample (HD-2700)}

Position 1 (SiC-reaction layer)
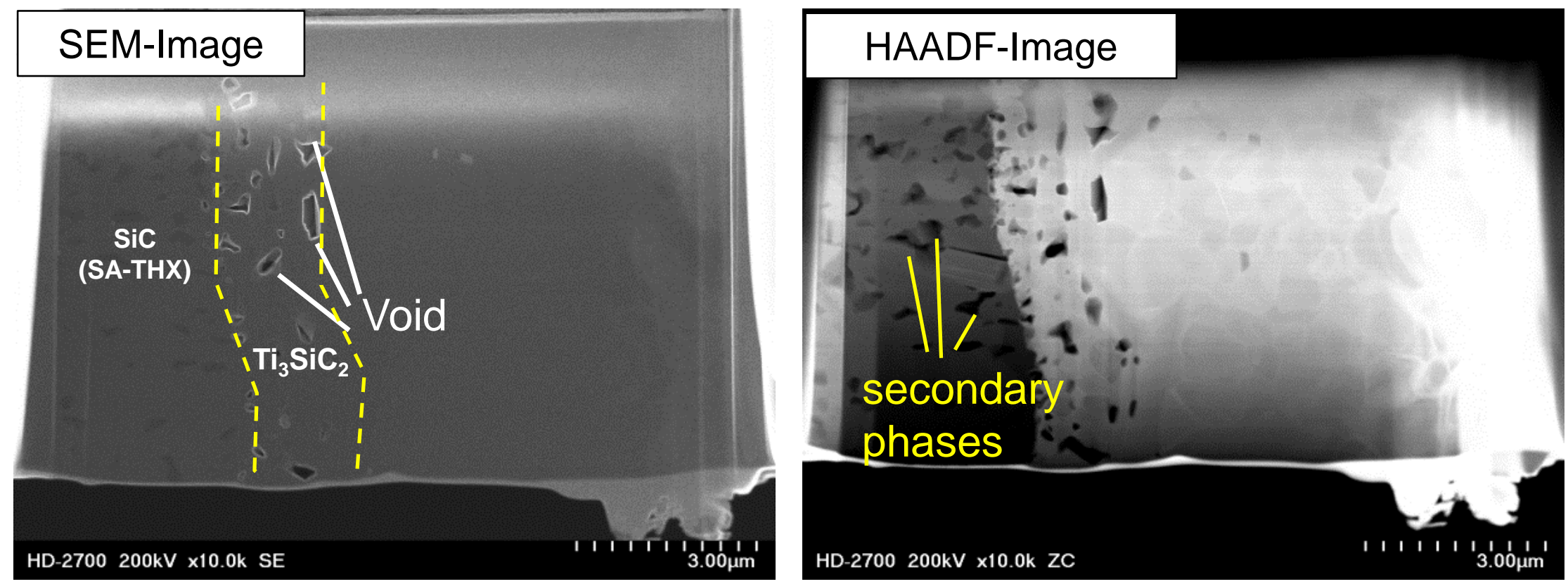

Ti3SiC2 phase

Some voids exist.

SA-THX phase Some precipitations (secondary phase) exist. 


\section{STEM images (obtained from SA-THX area.)}

\section{SEM}

\section{BF-STEM}

\section{HAADF}

7osaka 性双听 Lets Iry with I KI!
Only in HAADF-image, the contrast is observed clearly.

$\Rightarrow$ The precipitations is light element. (probably carbon) 


\section{STEM images (obtained from SA-THX area.)}

near the boundary of the SA-THX fiber

\section{SEM}

\section{HAADF}

TITITI $800 \mathrm{~nm}$ HD-2700 200kV x40.0k ZC

\section{BF-STEM}
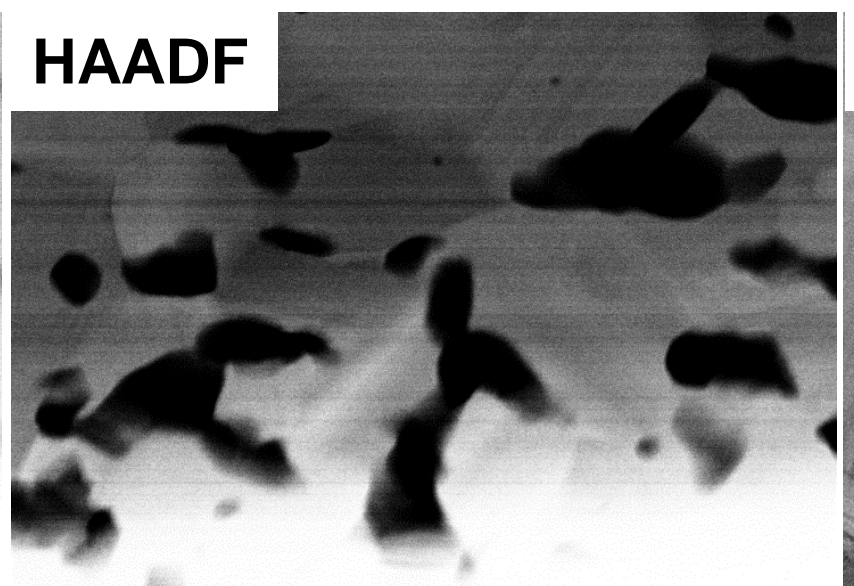

\section{BF-STEM}

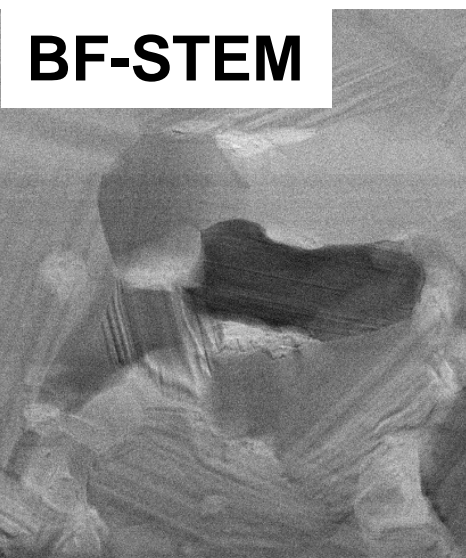




\section{SA-THX forming process}

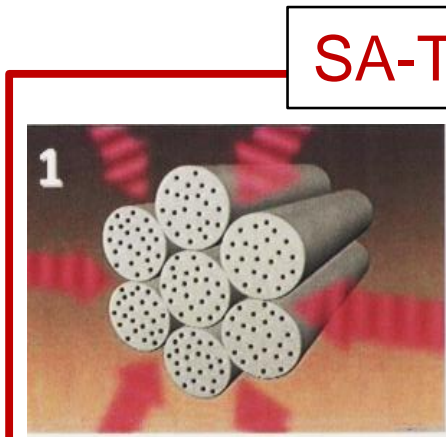

Under high pressure \& high temp. In hot press

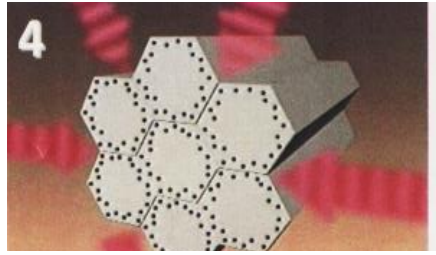

Diffusion transports carbon from the center of fibers to its surface

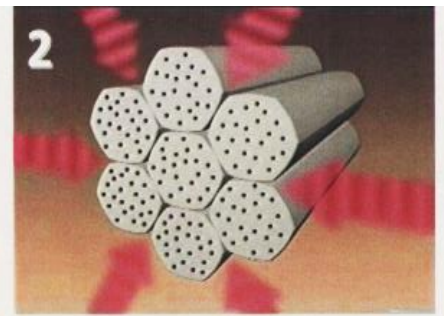

Deforming fibers \& Evaporating $\mathrm{SiO}$ and $\mathrm{CO}$ gas

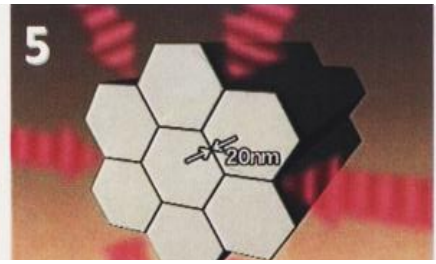

Unique SA-Tyrannohex structure

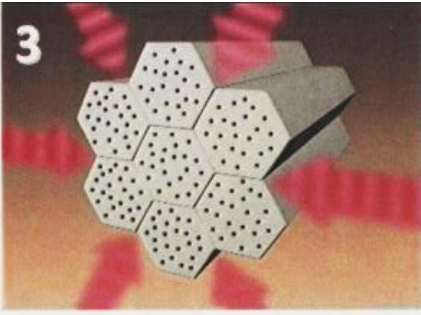

Closed-pack hexagonal columnar structure

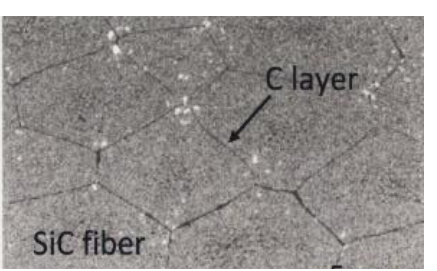

SEM microstructure of SA-TX surface

\section{Position 1 (SiC-reaction layer)}

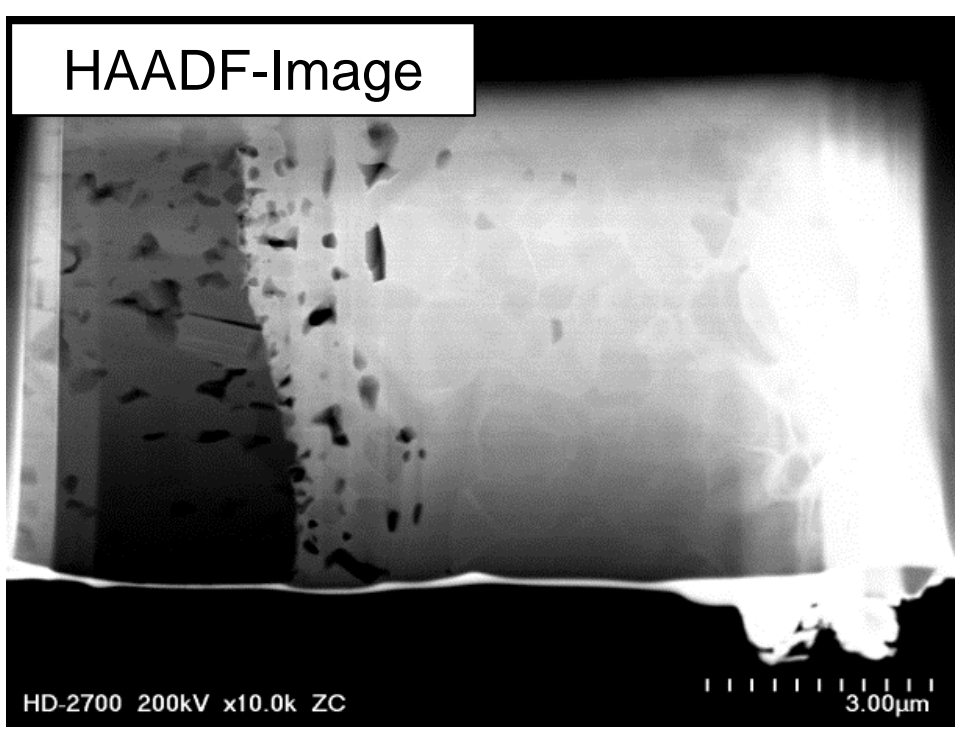

The precipitations are not observed in the reaction layer.

The precipitations don't affect diffusion bonding quality a lot?

A-THX has been developed by Dr. T. Ishikawa et al.

T. Ishikawa et al, Nature, 391, 773-775 (1998).

Also, SA-THX is consisting of a highly ordered, closed-packed structure of very fine hexagonal columnar fibers, with a thin interfacial carbon layer between the fibers. The interior of the fiber element was composed of sintered crystalline $\beta$-SiC.

\section{$\Rightarrow$ These precipitations stem from} residual carbon in SA-THX forming. 


\section{Objectives}

We diffusion bonded SiC and SiC ( $\underline{\underline{S A}-\mathrm{THX} \text { and SA-THX) }}$

using Ti-Mo foil metallic interlayer.

We carried out TEM and STEM observations with the diffusion

bonded sample prepared by FIB technique.

1. Evaluate microstructures of the diffusion bonded SA-THX by TEM and STEM.

2. Characterize the complex microstructure in the diffusion bonded area by TEM observation and SAED analysis. 
TEM image and SAD patterns of diffusion bond (Ti-Mo foil)

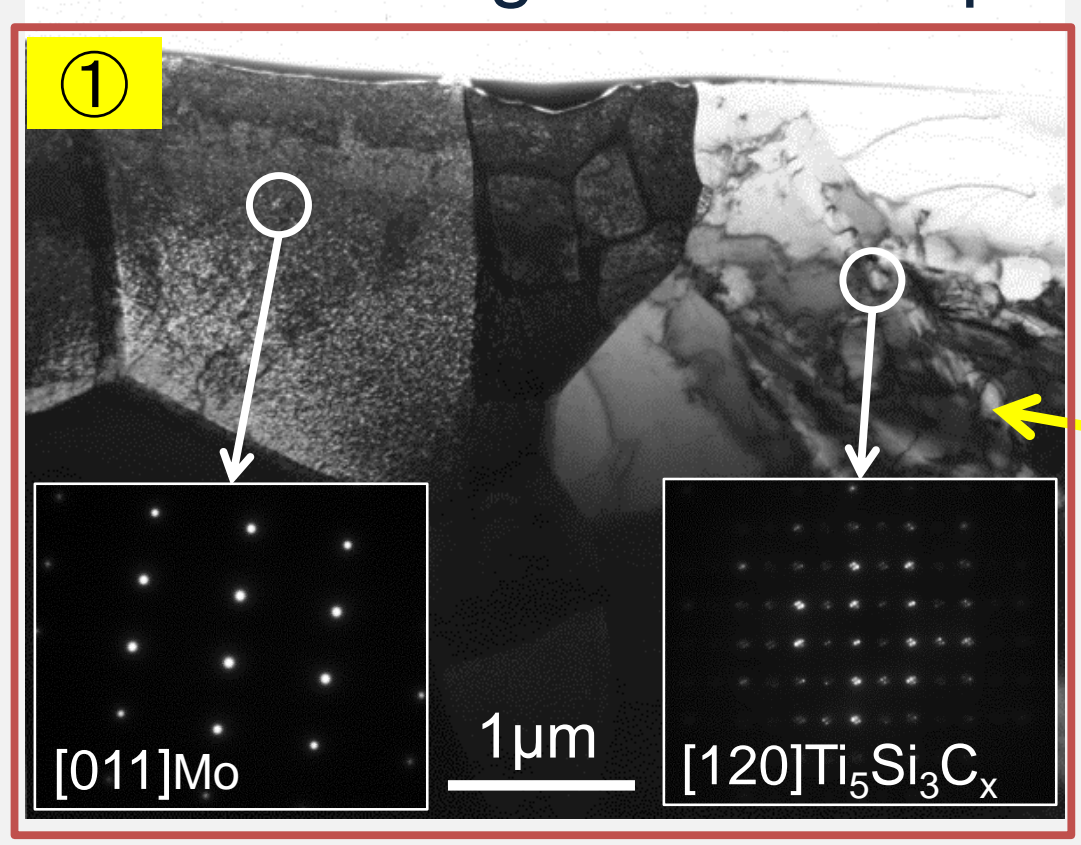

@CMCEE11
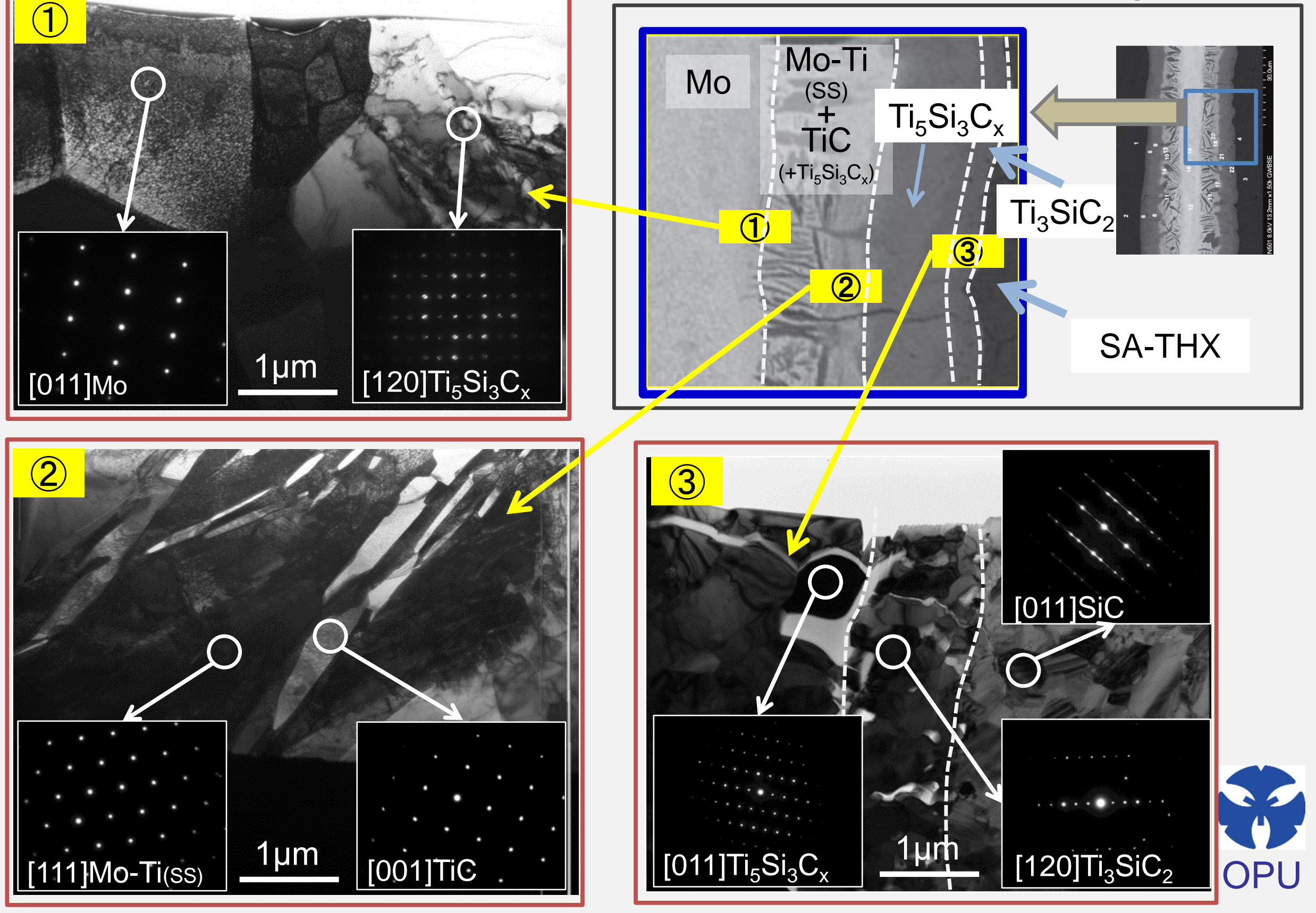


\section{STEM image of diffusion bond}
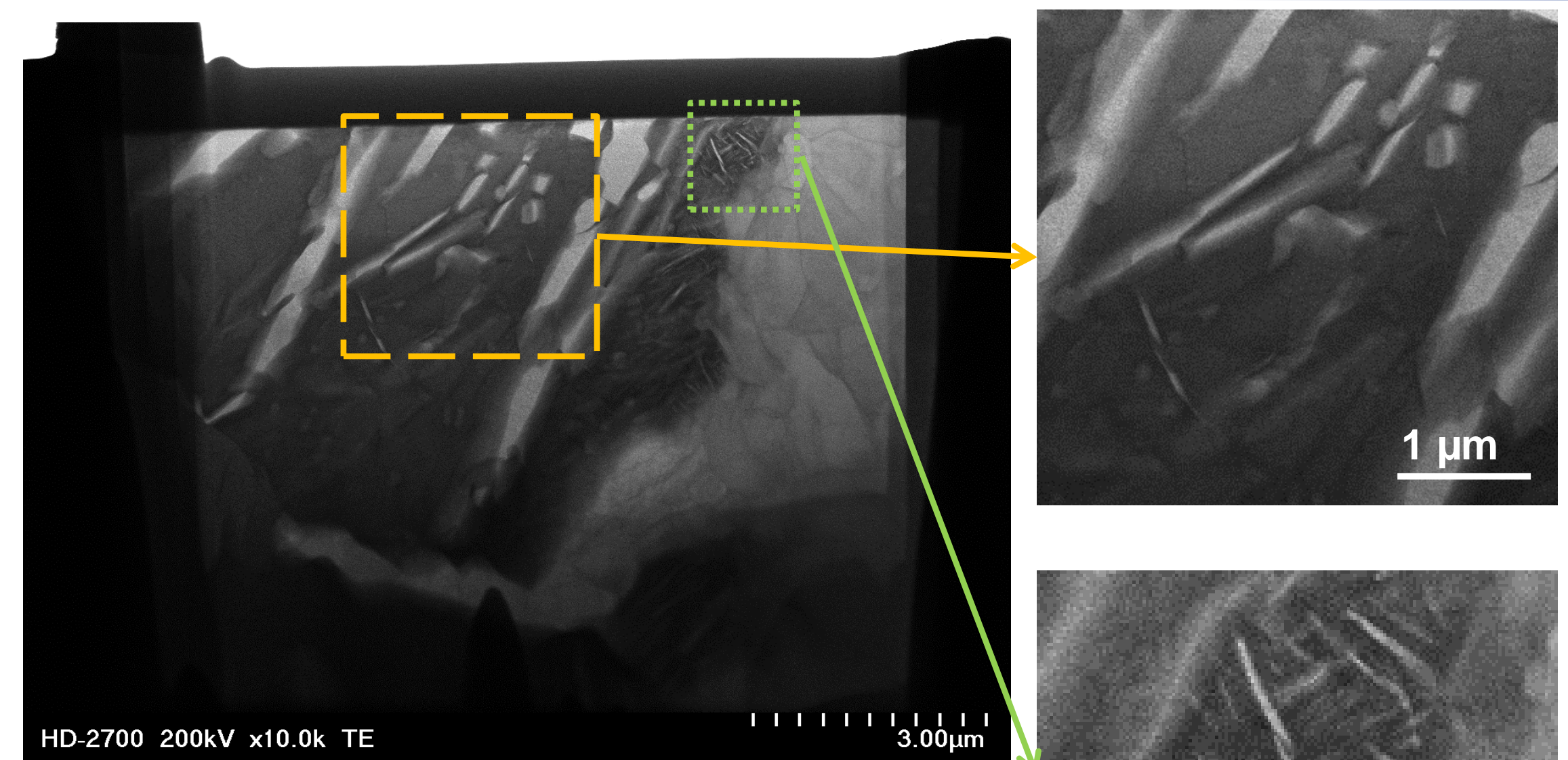

coarse and fine TiC pillars 


\section{TEM image and SAED patterns of TiC pillar}

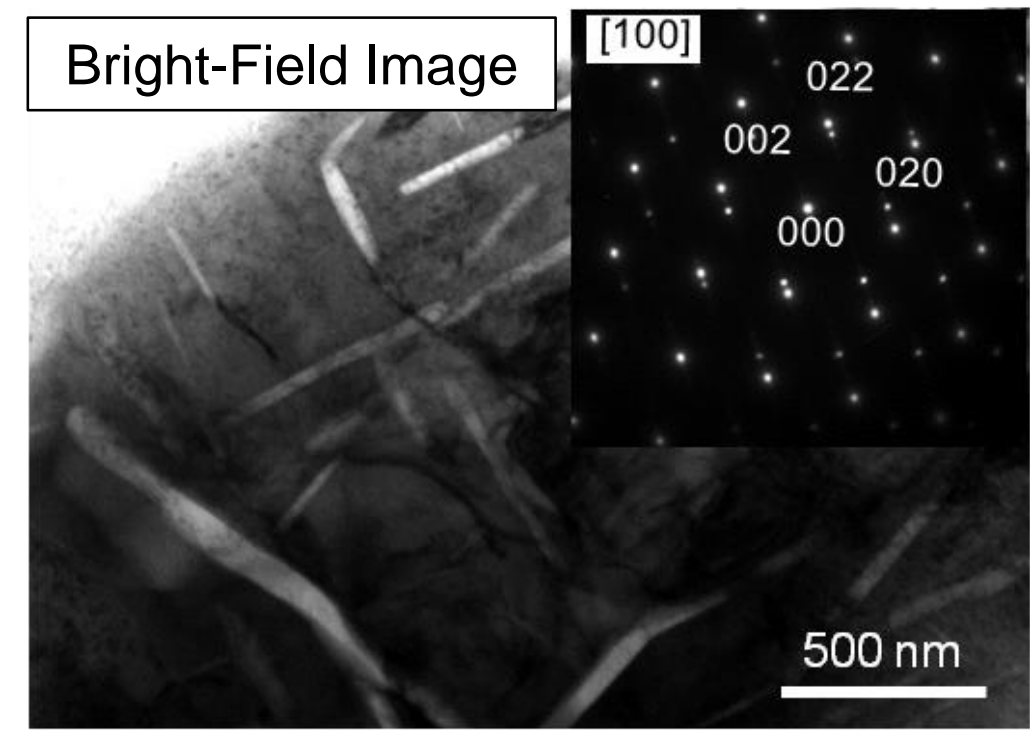

Schematic image of the location of $\mathrm{TiC}$ in [Mo-Ti]ss matrix.
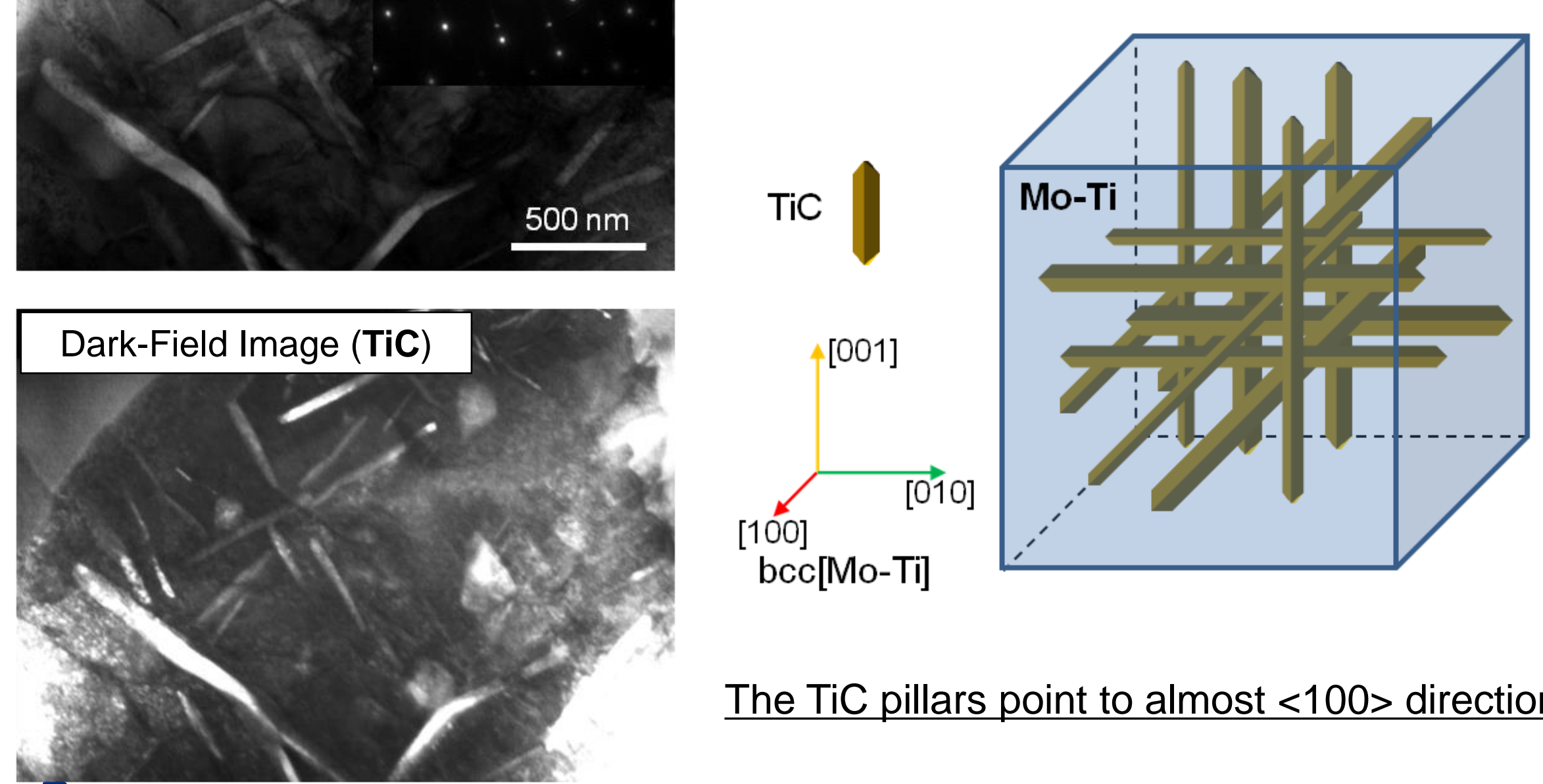

The TiC pillars point to almost $<100>$ direction.

TiC

1

bcc[Mo-Ti] 

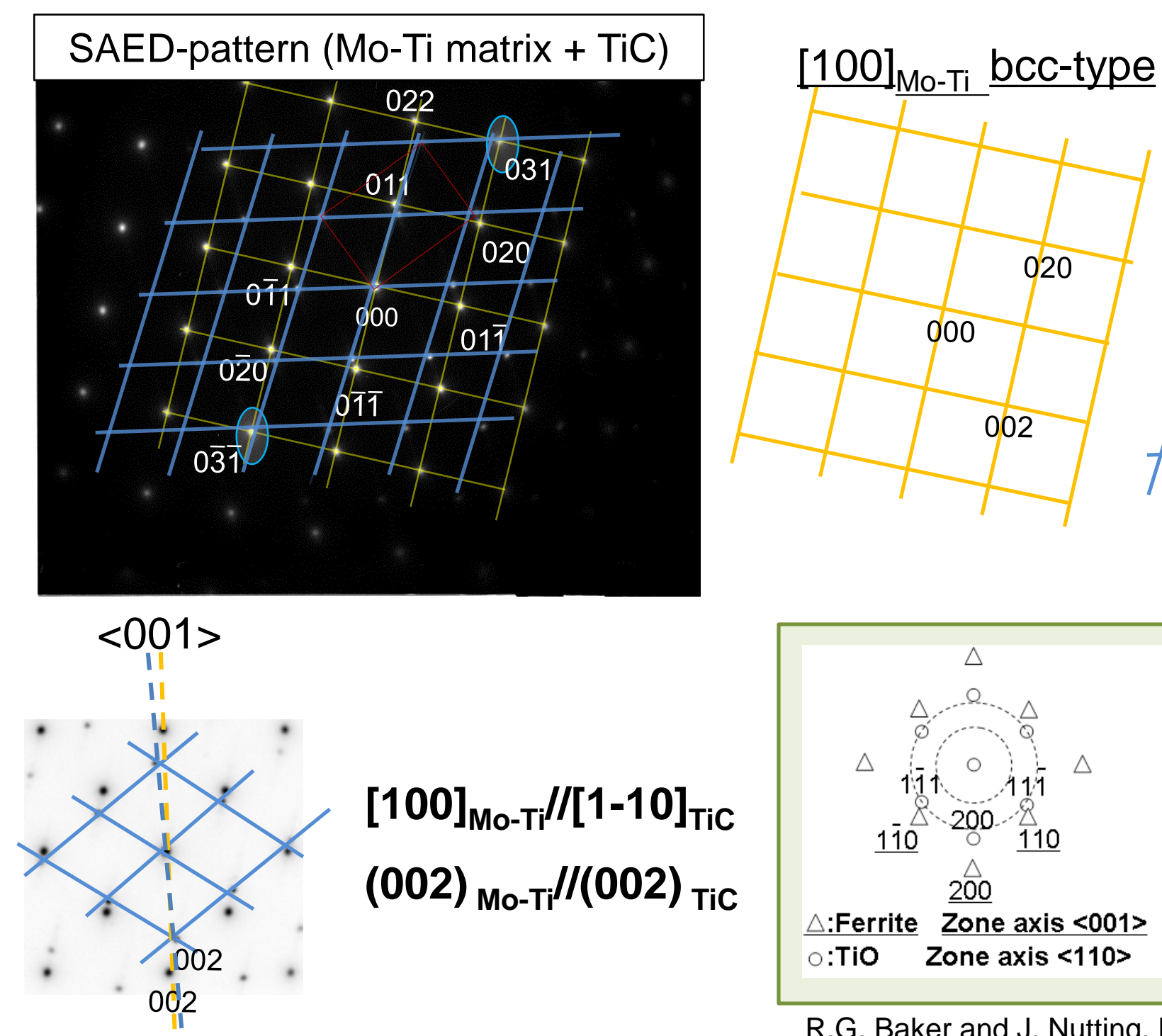

$[100]_{\text {Mo-Ti }} / /[1-10]_{\text {TiC }}$ $(002)_{\text {Mo-Ti }} / /(002)_{\text {TiC }}$

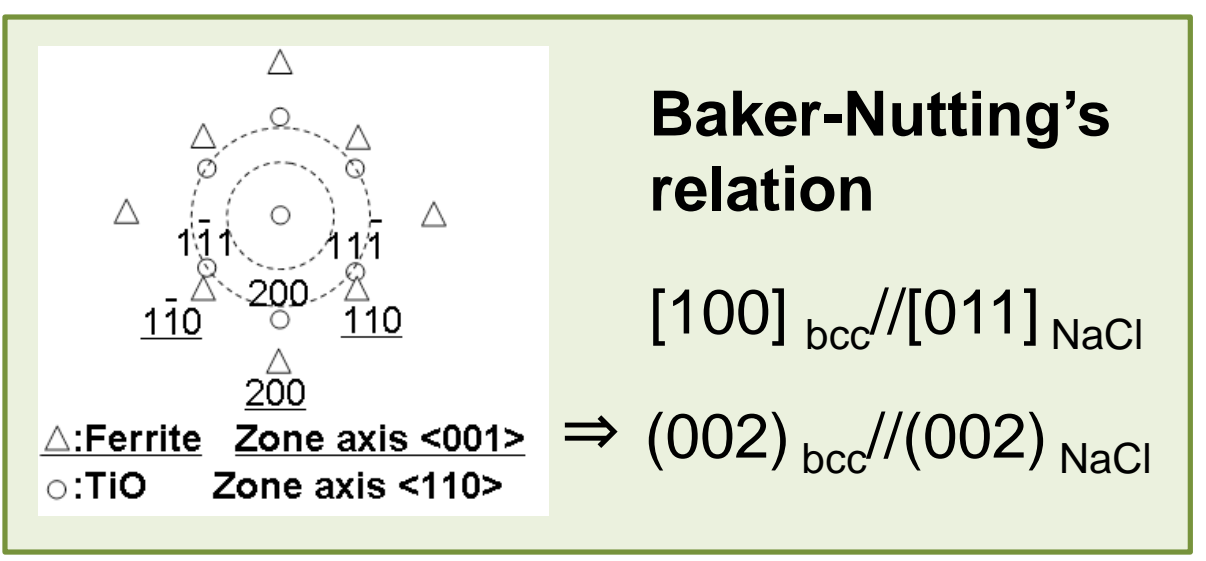

R.G. Baker and J. Nutting, Precipitation Process in Steels, I.S.I. Special report,No. 64 (1959).

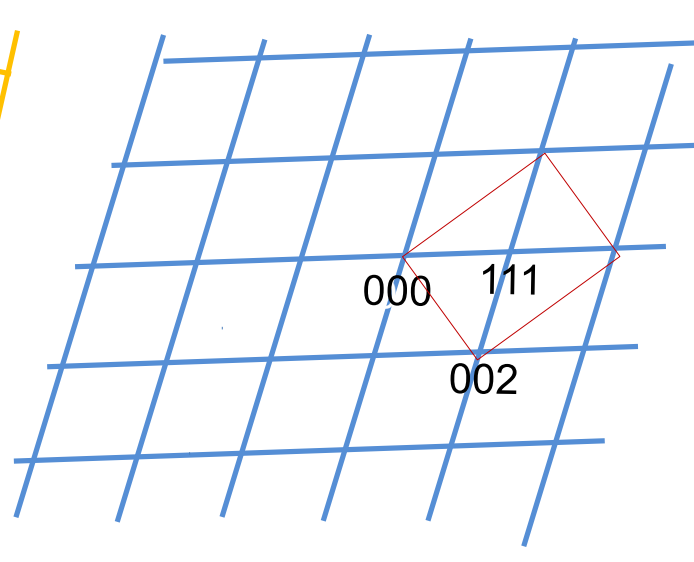




\section{Summary}

$>1$. We picked up thin samples from the bonded area of diffusion bonded SA-THX by a FIB micro-sampling technique. The prepared thin samples were sufficiently thin and less-damaged, and allowed the detailed evaluation by TEM and STEM.

$>$ 2. Submicron-sized carbon precipitations were observed in the SA-THX phase away from the boundary of SA-THX fiber. These precipitations did not exist in the reaction phase. It indicates that these precipitations will not affect the diffusion bonding quality a lot.

> 3. TiC pillars were observed around the reaction layer which has a complicated microstructure. The TiC had an orientation relation with the

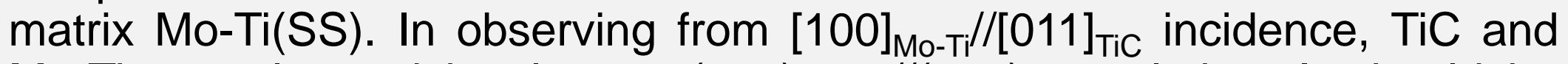
Mo-Ti were located in almost $(002)_{\mathrm{Mo}_{\mathrm{TI}}} \mathrm{l} /(002)_{\mathrm{TiC}}$ relation. It should be considered that precipitated $\mathrm{TiC}$ and matrix Mo-Ti has Baker-Nutting's relation that is often seen when $\mathrm{NaCl}$-type material precipitates in a matrix of bcc-type materials. 